\title{
Activating FGFR3 Gene Mutation
}

National Cancer Institute

\section{Source}

National Cancer Institute. Activating FGFR3 Gene Mutation. NCI Thesaurus. Code C142132.

A change in the nucleotide sequence of the FGFR3 gene that that results in constitutive activation of fibroblast growth factor 3 and its downstream signaling pathways. 